ARTICLE

https://doi.org/10.1038/s41467-019-12838-7

\title{
Fouling-resistant biofilter of an anaerobic electrochemical membrane reactor
}

\author{
Qilin Yu (1) ${ }^{1} \&$ Yaobin Zhang (1D ${ }^{1 *}$
}

\begin{abstract}
Membrane fouling is a considerable challenge for the stable operation of anaerobic membrane-based bioreactors. Membrane used as a cathode is a common measure to retard fouling growth in anaerobic electrochemical membrane bioreactors (AnEMBR), which; however, cannot avoid the fouling growth. Here we report a strategy using the membrane as an anode to resist membrane fouling in an AnEMBR. Although aggravating in the initial stage, the fouling on the anode membrane is gradually alleviated by the anode oxidation with enriching exoelectrogens to finally achieve a dynamic equilibrium between fouling growth and decomposition to maintain the operation stable. A mesh-like biofilter layer composed of cells with less extracellular polymeric substance (EPS) is formed on the membrane surface to lower the trans-membrane pressure and promote the interception of the anode membrane. The membrane has high electron storage and transfer capacities to accelerate the oxidation of the intercepted fouling materials, especially, the redundant EPSs of the biofilter layer.
\end{abstract}

\footnotetext{
${ }^{1}$ Key Laboratory of Industrial Ecology and Environmental Engineering (Dalian University of Technology), Ministry of Education, School of Environmental Science and Technology, Dalian University of Technology, Dalian 116024, China. *email: zhangyb@dlut.edu.cn
} 
ntegration of anaerobic digester with membrane bioreactor technology (AnMBR) is an eco-friendly and promising solution for the treatment of wastewater, which leads to clean energy generation and high effluent quality ${ }^{1}$. However, membrane fouling is a considerable challenge for the stable operation of AnMBR, though the produced biogas may sparge the surface of the membrane to alleviate the fouling ${ }^{2-4}$. Plentiful methods have been attempted to resist the membrane fouling ${ }^{5-7}$. AnEMBR, commonly utilizing the inherent biofouling control of the cathode related to electrostatic repulsion and in situ production of biogas $\left(\mathrm{H}_{2}\right.$ or $\left.\mathrm{CH}_{4}\right)$ via cathode reduction of $\mathrm{H}^{+}$or $\mathrm{CO}_{2}$, could significantly slow down the formation of sludge cake layer on membrane surface ${ }^{8}$. However, the fouling can still be accumulated on the cathode membrane and plug membrane pore with operation eventually ${ }^{9,10}$. Therefore, developing a method to effectively resist the fouling of anaerobic membrane reactor is highly desirable to maintain its durable operation.

Until now, membranes were rarely utilized as the anode of AnMBR because the electrostatic adherence in the anode aggravates the fouling to decrease effluent flux. However, the sludge cake layer formed on the membrane potentially improves the effluent quality since the fouling layer can actually serve as a filter to intercept small particles ${ }^{11}$, just like the sludge cake layer formed on the sand surface of a sand-filter tank, which can make the effluent increasingly clean with operation before backwashing. Once the fouling is maintained to a certain extent to intercept particles and ensure the sufficient water flux through the cake layer, the pore size of membrane is not required to be quite small to directly intercept the particles, but can be amplified to lessen the fouling that blocks in the pores.

Complex organics such as proteins and polysaccharides have been reported to be decomposed in the anode of the bioelectrochemical system via microbial anodic oxidation ${ }^{12-14}$. During this process, electrons produced from oxidation of organics by exoelectrogens are extracellularly transferred to the anode for electricity generation. The manners of extracellular electron transfer of exoelectrogens include direct contact of extracellular nanowires such as pili, electron shuttle, and so on ${ }^{15,16}$. As is well known, proteins and polysaccharides are the main constituents of the extracellular polymeric substances (EPS), and EPS as well as microbial cells contribute a majority of the membrane fouling of $\mathrm{MBR}^{17,18}$. Therefore, using the membrane as the anode is likely to decompose the membrane fouling via the microbial anode oxidation, and once the decomposition rate is approximately equal to or higher than the fouling growth rate, the fouling would not be accumulated and even alleviated to enable the stable operation of the AnMBR. Meanwhile, the cells and residual EPS on the anodic membrane are expected to form a biofilter layer with less resistance to purify the effluent.

In this study, a membrane with large apertures is applied as the anode of an AnMBR to investigate its antifouling performance. We expect that the sludge cake layer formed on the anode membrane surface functions as a fouling-resistant biofilter to intercept particles of the effluent, and the mechanisms of fouling decomposition and fouling roles are explored.

\section{Results}

Trans-membrane pressure profiles along the operation. The continuous operation of the membrane reactors increased transmembrane pressure (TMP) and decreased the permeate flux due to the membrane fouling. The obvious vibration of TMP observed in the three reactors (Fig. 1a) could be attributed to the agitation of biogas produced from digestion and the biodegradation of fouling, which might in part alleviate membrane fouling though their effects were weak and unable to maintain the operation
R-M: Membrane without potential applied

R-0.3: Membrane with $-0.30 \mathrm{~V}$ potential applied

R-0.2: Membrane with $-0.20 \mathrm{~V}$ potential applied

a
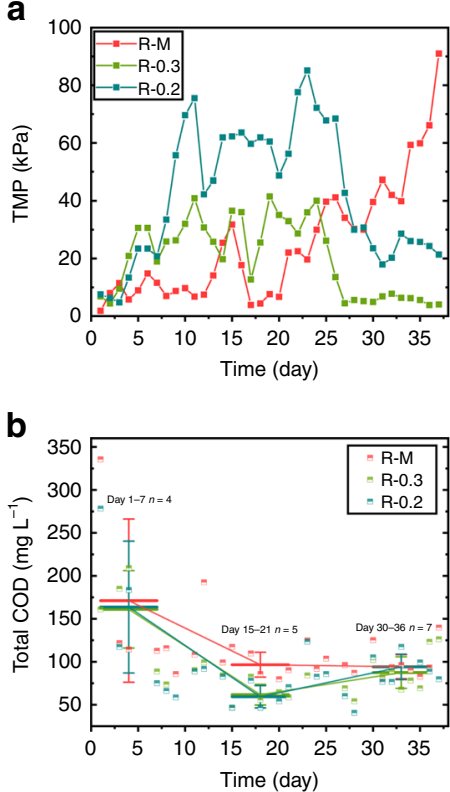

C
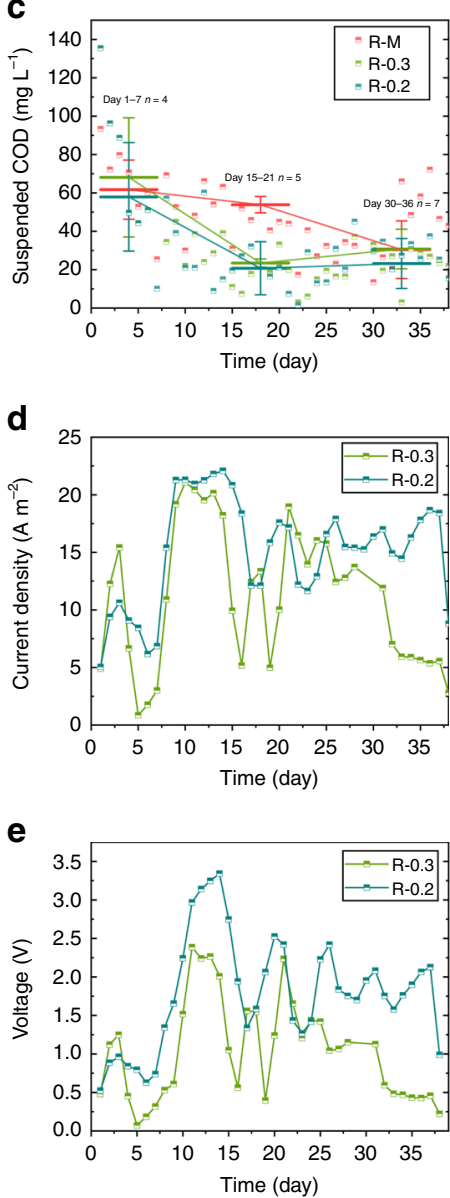

stable. Especially, the electrostatic adsorption and EPS secretion with the electric stimulation further intensified the fouling, leading to faster increases of TMP of the two electro-membrane reactors (R-0.3 applied with $-0.3-\mathrm{V}$ anode potential and $\mathrm{R}-0.2$ applied with $-0.2-\mathrm{V}$ anode potential) in the initial days. Accordingly, on day 11, the TMP of the two electro-membrane 
Fig. 1 Reactor performances along operation. a TMP, $\mathbf{b}$ total COD, c suspended COD, $\mathbf{d}$ current density, and $\mathbf{e}$ voltage profiles of the control reactor (R-M: membrane without potential applied) and the electromembrane reactors $\mathrm{R}-0.3$ (membrane with $-0.30-\mathrm{V}$ potential applied) and $\mathrm{R}-0.2$ (membrane with $-0.20-\mathrm{V}$ potential applied). (Numbers that follow the \pm signs are standard deviation (SD) in this study. Error bars in (b) and (c) are from Day 1 to $7(n=4)$, from Day 15 to $21(n=5)$, and from Day 30 to $36(n=7)$. Source data are provided as a Source Data file.)

reactors (R-0.3 and R-0.2) was 40.90 and $75.53 \mathrm{kPa}$, respectively, compared with $6.78 \mathrm{kPa}$ of the control membrane reactor $(\mathrm{R}-\mathrm{M}$ with no potential applied). Afterward, TMP of the two electromembrane reactors began to decrease from day 25 and maintained at low levels that averaged at $5.52 \pm 1.15 \mathrm{kPa}$ for R-0.3 and $26.49 \pm 6.41 \mathrm{kPa}$ for $\mathrm{R}-0.2$ during days $27-37$, respectively (numbers that follow the \pm sign are standard deviation (SD) in this study). The decrease in TMP suggested that cleansing fouling with anodic potentials was gradually enhanced to exceed the fouling growth. The TMP at low levels indicated the equilibrium between the cleaning and the growth of the fouling on the anode membrane. Contrary to the two electro-membrane reactors, the overall TMP of the R-M presented a significant upward trend from day 20 , and eventually exceeded the threshold to cause breakdown finally.

The stable TMP of the electro-membrane reactors was likely due to anodic oxidation of substrates adsorbed on the membrane that outcompeted the fouling accumulation. In agreement, it has been extensively reported that the anode oxidation intensified the decomposition of organic substrates, including complicated substrates like EPS. The reduction of the fouling might be a result of gradual enrichment of exoelectrogens on the membrane, which drove the anodic oxidation of organic matters to remit the fouling and finally maintained the operation stable. The TMP of the R- 0.3 was lower than that of the R- 0.2 over the operation, indicating that the membrane with the lower anode potential applied was safer for operation.

Interception performance of the membranes. The electromembranes promoted the total chemical oxygen demand (TCOD) removal with a lower COD concentration in the effluent (Fig. 1b). With the increase in the TMP, the TCOD of the R-M decreased from $171.20 \pm 94.98 \mathrm{mg} \mathrm{L}^{-1}$ (from day 1 to $7, n=4$ ) to $96.61 \pm 14.47 \mathrm{mg} \mathrm{L}^{-1}$ (from day 15 to $21, n=5$ ), which was higher than that of the electro-assisted reactor (R-0.3: from $161.02 \pm 45.05$ to $61.70 \pm 12.04 \mathrm{mg} \mathrm{L}^{-1}$ and R-0.2: from $163.66 \pm$ 76.68 to $59.29 \pm 12.93 \mathrm{mg} \mathrm{L}^{-1}$ ). After day 30 , the three reactors reached the approximately same TCOD at the end of the operation. It indicated that the higher TMP of R-M (Fig.1a) was beneficial for the sludge cake layer to intercept particles, and the sludge cake layer formed on the membrane actually acted as a filter to intercept particles. From Fig. 1c, the average suspended COD of the two electro-membrane reactors (R-0.3 and R-0.2) decreased from $68.11 \pm 31.06$ and $57.95 \pm 28.29 \mathrm{mg} \mathrm{L}^{-1}$ (during days $1-7, \mathrm{n}=4$ ) to $23.48 \pm 2.13$ and $20.77 \pm 13.84 \mathrm{mg} \mathrm{L}^{-1}$ (during days $15-21, \mathrm{n}=5$ ), respectively, along with TMP increasing during the same periods. Similarly, the suspended COD of the control reactor R-M also decreased with increasing TMP, but at day 38 , the suspended COD of the R-M increased sharply to $102.4 \mathrm{mg} \mathrm{L}^{-1}$, indicating the breaking up of the membrane. However, the decrease in TMP of the two electro-membranes (Fig. 1a) did not bring down their interception performances, but the membranes maintained high removals of suspended COD. From day 30 to 36, the average suspended COD levels of R-0.3 and R-0.2 were $30.81 \pm 10.32$ and $23.22 \pm 13.03 \mathrm{mg} \mathrm{L}^{-1}(\mathrm{n}=7)$, respectively, compared with $68.11 \pm 31.06$ and $57.95 \pm 28.29 \mathrm{mg} \mathrm{L}^{-1}$ in the initial stage of the two reactors (Fig. 1c). The interception of the two electro-membranes was almost synchronous with changes in TMP. Furthermore, a higher TMP or a thicker cake layer was required for $\mathrm{R}-\mathrm{M}$ to intercept the similar level of suspended COD as the electro-membrane groups. On day 32, the suspended COD of the $\mathrm{R}-\mathrm{M}$ was $33.54 \mathrm{mg} \mathrm{L}^{-1}$ with its TMP at $42.09 \mathrm{kPa}$, while the similar suspended COD of the R- 0.3 $\left(33.11 \mathrm{mg} \mathrm{L}^{-1}\right)$ and the R-0.2 $\left(27.09 \mathrm{mg} \mathrm{L}^{-1}\right)$ was obtained with the TMP only at 7.75 and $20.26 \mathrm{kPa}$, respectively. The high interception capacity but lower fouling in the two electromembrane reactors implied that the composition or structure of the sludge cake layer attached on the membrane surface was likely changed to reserve the filter capacity.

Electric signal changes of the electro-assisted membrane. The current density detected between the anode and cathode is a result of the anodic oxidation driven by exoelectrogens ${ }^{16}$. From Fig. 1d, the current density of the two electro-membrane reactors sharply increased from the 6th day, likely due to the enrichment of exoelectrogens to enhance anodic oxidation and electric production. EPS, a main composition of the fouling, could serve as an organic substrate for anodic oxidation. With increasing of the anode oxidation, the fouling was decomposed to thin the sludge cake layer that resulted in the decrease in TMP. The consumption of EPS on the electro-membrane eventually led to the inadequacy of substrates for the anodic oxidation, and correspondingly the electric current density began to decay from day 15 . As the cake layer became thinner, the electrostatic adherence of organic matters on the surface of the cake layer on the electro-membrane was enhanced due to the gradient distribution of the electric field. Thus, the adsorbed organics could also serve as the substrate to supplement the inadequate EPS for anode oxidation. Eventually, the fouling growth resulted from the interception, and the fouling cleaning by the anodic oxidation reached the dynamic equilibrium to maintain the operation stable.

As shown in Fig. 1e, the profiles of the voltage of the reactors agreed with the above results. The average voltage between the anode and cathode was about $1.86 \pm 0.21 \mathrm{~V}$ in the R-0.2, which was higher than that in the R- $0.3(0.48 \pm 0.06 \mathrm{~V})$ at the final operation stage (from days 32 to $37, n=6$ ). It was reported that excessive voltage (higher than $0.80 \mathrm{~V}$ ) was harmful to the anaerobic microbes ${ }^{19}$. Clearly, the lower voltage of $\mathrm{R}-0.3$ was preferred for the anaerobic microbes.

Cross-profile and surface morphology of the membranes. A microscope and scanning electron microscope (SEM) were used to observe the morphologies of the membranes at the end of the operation. The membranes of $\mathrm{R}-\mathrm{M}$ and $\mathrm{R}-0.3$ were characterized to investigate the effects of anodic potential on the membrane fouling. From the cross section of the membrane in Fig. 2a, b, a thick sludge cake layer $(32.20-62.56 \mu \mathrm{m})$ was observed on the membrane surface of $\mathrm{R}-\mathrm{M}$, while a thin sludge cake layer $(18.00-31.50 \mu \mathrm{m})$ was obtained with the anode potential applied. The thin sludge cake layer indicated the alleviation of fouling with the potential on the anodic membrane, while the thick sludge cake layer indicated the heavy fouling without the potential. From the SEM analysis (Fig. 2c, d), the cells of the sludge cake layer on the membrane without electro-assistance were encysted with compact EPS-like matters that were huddled together to form dense structures, which might efficiently intercept suspended matters (Fig. 1c) and increase TMP (Fig. 1a). Comparatively, a clear array of sludge cell appeared on the anode membrane, in which the gaps of cells were visible with less extracellular substrates to seemingly form mesh-like sludge cake structures. The 


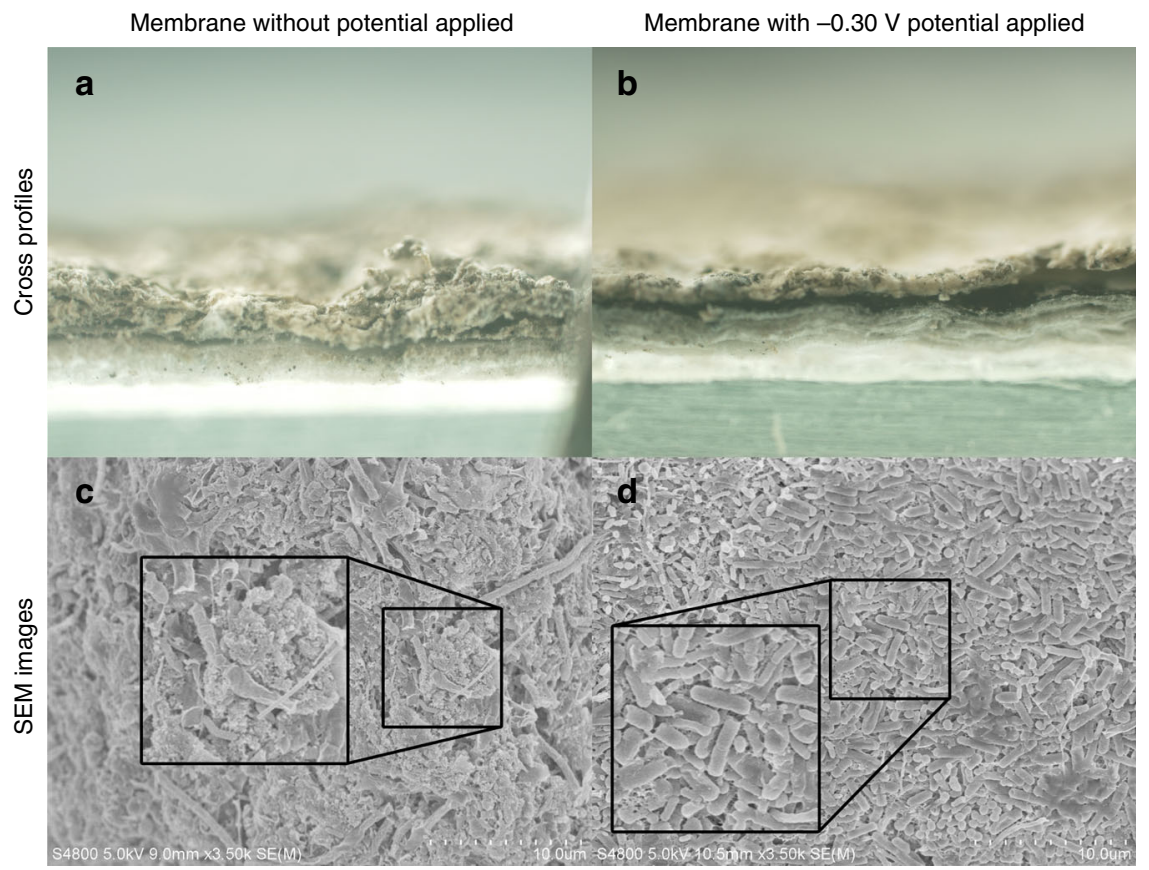

Fig. 2 Morphologies of the membranes. Cross-profiles of a the control membrane (R-M: membrane without potential applied) and $\mathbf{b}$ the electro-membrane (R-0.3: membrane with $-0.30-\mathrm{V}$ potential applied). Surfaces morphologies of the sludge cake layers of $\mathbf{c}$ the control membrane and $\mathbf{d}$ electro-membrane. (Membranes were taken out at day 38)

mesh-like structures formed by the well-aligned stacking of cells of the anodic microbes could function as a biofilter membrane to hold back suspended matters to obtain a higher effluent quality as well as maintain a high water flux. It indicated that an anodic potential imposed on the membrane could cleanse the majority of fouling including EPS. Namely, the EPS and suspended matters of the sludge cake layer of the electro-membrane could be biodegraded by the anodic oxidation, which caused the cells with less EPS-like matters or others wrapped to form the mesh-like biofilter to obtain the high filtration efficiency and low TMP.

Fouling distribution on the sludge cake layers. Percentages of total cells, proteins, and polysaccharides in the sludge cake layer were detected by confocal laser scanning microscopy (CLSM) (Fig. 3a, b). The fluorescence intensities of total cells (red), proteins (green), $\beta$-polysaccharides (blue), and $\alpha$-polysaccharides (purple) of the electro-membrane (Fig. 3b) were significantly weaker than those of the control membrane (Fig. 3a), showing that the fouling, mainly consisting of cells, proteins, and polysaccharides, was alleviated with the anodic potential. However, from the calculation of the intensities (Table 1), with the anodic potential imposed on the membrane, the intensity percentage of the total cell increased from 25.06 to $38.06 \%$, along with the decrease in the intensity percentages of proteins and polysaccharides surrounding cells, which was well in agreement with the mesh-like cell stacking with less EPS wrapped (Fig. 2). Especially, the proteins and polysaccharides intensity of per cell decreased from 1.17 to 0.56 and 1.82 to 1.07 with the anodic potential, respectively, indicating that EPS such as proteins and polysaccharides was more likely to be decomposed compared with cells. The cells remaining on the sludge cake layer were exposed to form the mesh-like biofilter to improve the water flux and participate in anode oxidation.

Electrochemical performances of the membranes. EPS contains the functional groups such as proteins and carbonyl/hydroxyl

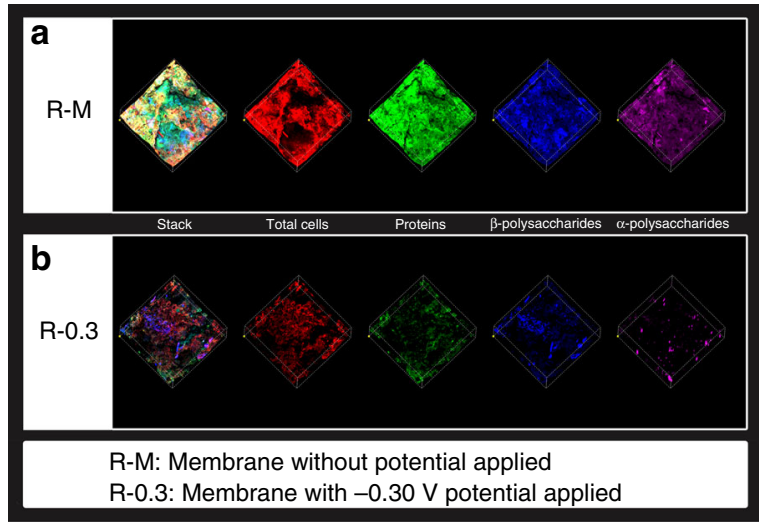

Fig. 3 CLSM images of a the control membrane (R-M: membrane without potential applied) and electro-membrane (R-0.3: membrane with $-0.30-\mathrm{V}$ potential applied). (Membranes were taken out at day 38)

that were believed redox-active to store electrons and mediate extracellularly the electron transfer of exoelectrogens ${ }^{20,21}$. Therefore, the decomposition of EPS such as proteins and polysaccharides would decrease its electroactivity for the anode oxidation. Reversely, the sludge cake layer of the electromembrane attained a much higher electron-storage capacity ${ }^{22}$ than that of the control membrane from the cyclic voltammogram (CV) curves in phosphate buffer solution (PBS) (Fig. 4a). It seemed that the electroactivity of the sludge cake layer was reserved during the decomposition of sludge cake layer.

From the electrochemical impedance spectrum (EIS) results (Fig. 4b), the resistance of the R-M membrane (including sludge cake layer and carbon nanotube (CNT) membrane) was significantly higher than that of the CNT membrane, while the resistance of anode membrane was approximate with the CNT membrane. The EIS data of three membranes were fitted with a 
Table. 1 Intensities of the total cells and EPSs in the sludge cake layers of the control membrane and electro-membrane

\begin{tabular}{lllllll} 
& Total cells & Proteins & $\boldsymbol{\beta}$-polysaccharides & $\boldsymbol{\alpha}$-Polysaccharides & Pn/TC & Ps/TC \\
\hline R-M & $11.32(25.06 \%)$ & $13.23(29.30 \%)$ & $9.47(20.96 \%)$ & $11.14(24.67 \%)$ & 1.17 \\
R-0.3 & $3.75(38.06 \%)$ & $2.09(21.20 \%)$ & $2.75(27.93 \%)$ & $1.26(12.80 \%)$ & 0.56 & 1.07 \\
\hline
\end{tabular}

Control membrane: R-M, membrane without potential applied; electromembrane: $\mathrm{R}-0.3$, membrane with $-0.30-\mathrm{V}$ potential applied; membranes were taken out at day 38 . Source data are provided as a Source Data file

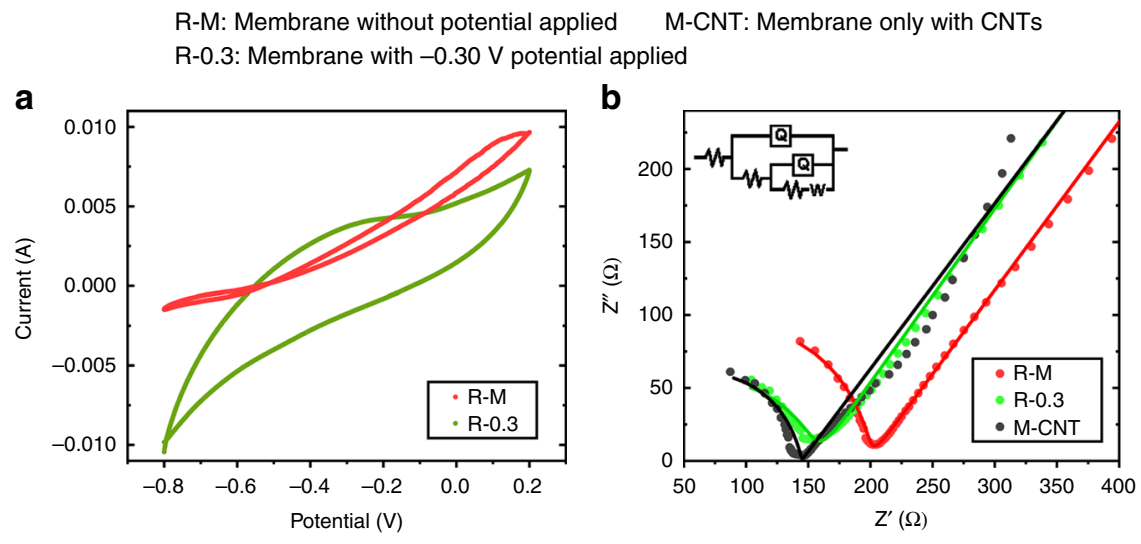

Fig. 4 Electrochemical performances of the membranes. a Cyclic voltammetric analyses of control membrane and electro-membrane in PBS solutions at a scan rate of $5 \mathrm{mV} / \mathrm{s}$. b Nyquist plots and the fitted data (solid line) according to the inserted equivalent circuit of CNT membrane (M-CNT: membrane only with CNTs), control membrane (R-M: membrane without potential applied), and electro-membrane (R-0.3: membrane with -0.30- $V$ potential applied). (Membranes were taken out at day 38. Source data are provided as a Source Data file.)

\begin{tabular}{|c|c|c|c|c|}
\hline & $\begin{array}{l}\text { Resistance } \\
(\Omega)\end{array}$ & $\begin{array}{l}\Delta \text { resistance } \\
(\Omega)\end{array}$ & $\begin{array}{l}\text { Thickness } \\
(\mu \mathrm{m})\end{array}$ & $\begin{array}{l}\text { Conductivity } \\
\left(10^{-4} \mathrm{~S} \mathrm{~m}^{-1}\right)\end{array}$ \\
\hline R-M & 198.4 & 54.0 & $32.20-62.56$ & $1.86-3.62$ \\
\hline$R-0.3$ & 156.2 & 11.8 & $18.00-31.50$ & $4.76-8.33$ \\
\hline
\end{tabular}

Control membrane: R-M, membrane without potential applied; electro-membrane: R-0.3, membrane with $-0.30-V$ potential applied; membranes were taken out at day 38 . Source data are provided as a Source Data file

simulated equivalent circuit to further depict the electrochemical properties of biofilter cake layer ${ }^{23}$. From the simulated results, the R-M membrane attained a higher membrane resistance $(202.5 \Omega)$ than the anode membrane (155.5 $\Omega$ ) and CNT membrane (146.0 $\Omega$ ), which meant that the conductivity of the sludge cake layer on $\mathrm{R}-0.3$ was about $1.32-4.48$-folds of that on the $\mathrm{R}-\mathrm{M}$ membrane referring to the layer thickness (Table 2). The higher conductivity of the sludge cake layer on the electro-membrane was beneficial for extracellular electron transfer of anode oxidation ${ }^{24}$.

Effect of anode potential on microbial community. Geobacter species, a typical exoelectrogen in bio-electrochemical systems ${ }^{25-27}$, was specifically enriched in the sludge cake layer of the electromembrane (Fig. 5). The abundance of Geobacter was $4.80 \%$, about 7.4 -folds as high as that of control membrane (0.65\%). Geobacter biocatalyzed the decomposition of fouling via the anodic oxidation to maintain the operation stable ${ }^{16,28}$. The enrichment of Geobacter with conductive pili might increase the electroactivity of sludge cake layer such as sludge conductivity ${ }^{29}$. Moreover, the abundance of fermentative bacteria such as Levilinea ${ }^{30,31}$ and Raoultella ${ }^{32}$ species that could utilize carbohydrates, amino acids, alcohols, lactate,

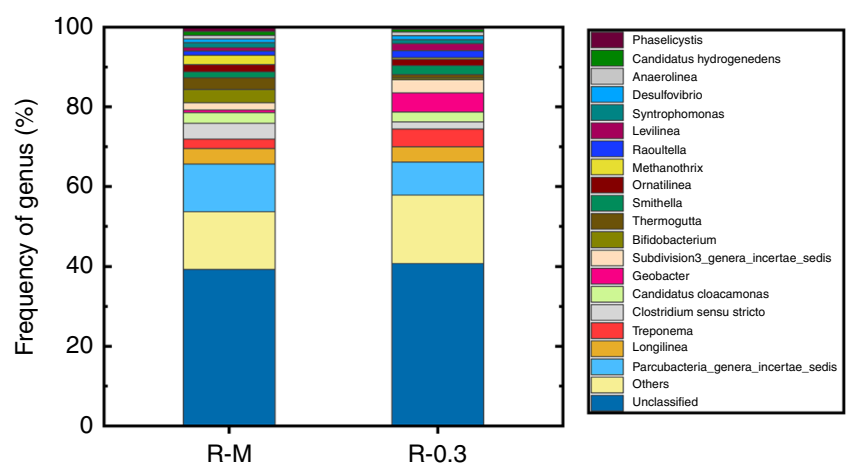

Fig. 5 Bacterial community structures of the sludge cake layers of the control membrane (R-M: membrane without potential applied) and electromembrane (R-0.3: membrane with $-0.30-V$ potential applied) after operation (at day 38). The genus level with relative abundance lower than $1.00 \%$ was classified into group "others". (Source data are provided as a Source Data file.)

pyruvate, and fumarate in the electromembrane was also higher than that in the control membrane. The metabolisms of the fermentative bacteria and the cooperation with exoelectrogens forwarded the efficient decomposition of fouling to maintain the electromembrane reactor that performed stably (see Supplementary Table 1).

Surface group variations and changes in electroactivity. The sludge cake layers were identified by electrochemical in situ Fourier transform-infrared (FTIR) spectroscopy to reveal the electrochemical activity at the molecular level. Bands that varied with potential shifting were related to redox reactions that occurred at the cell-electrode interface ${ }^{33}$. As shown in Fig. 6a-d, for the sludge cake layer of the control membrane, the intensities 

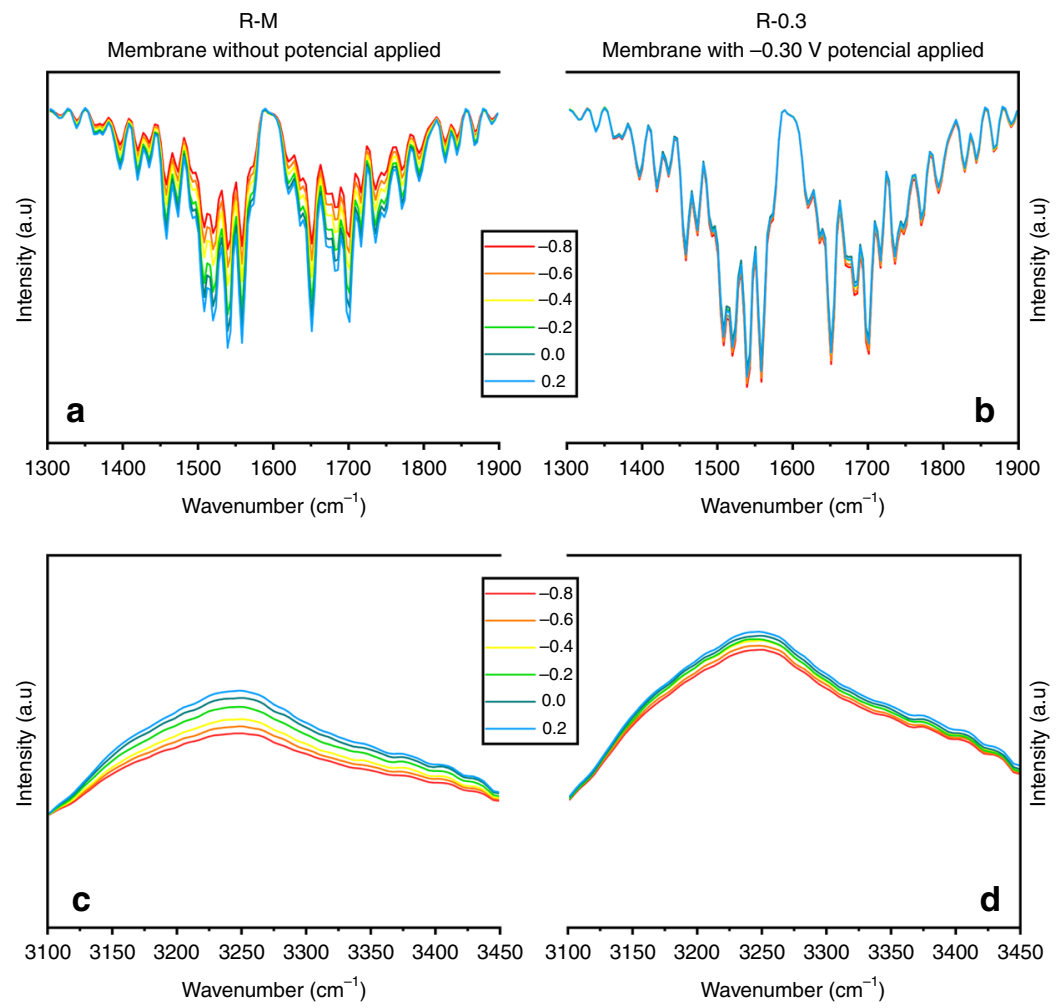

e

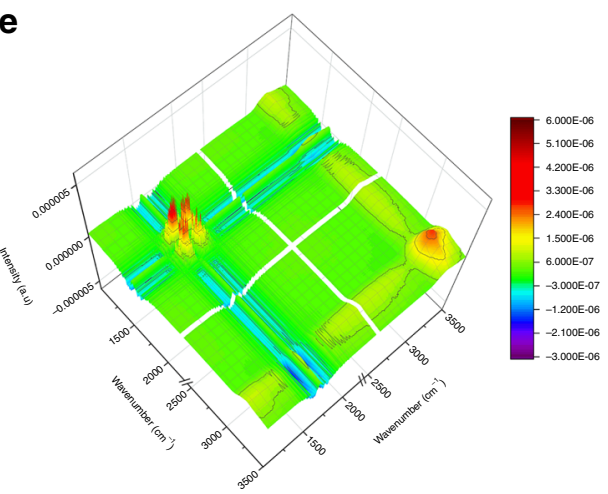

g

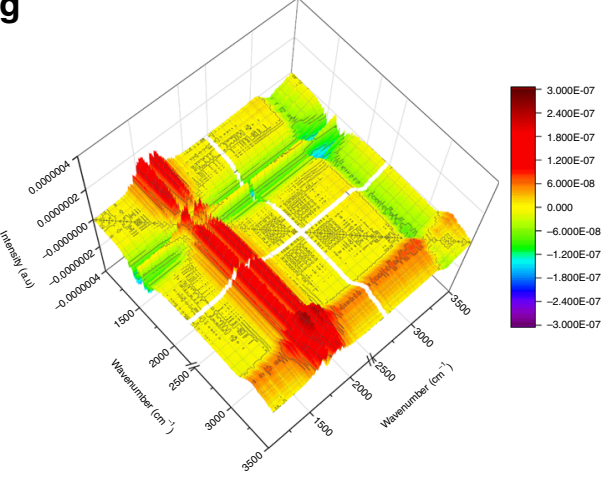

f

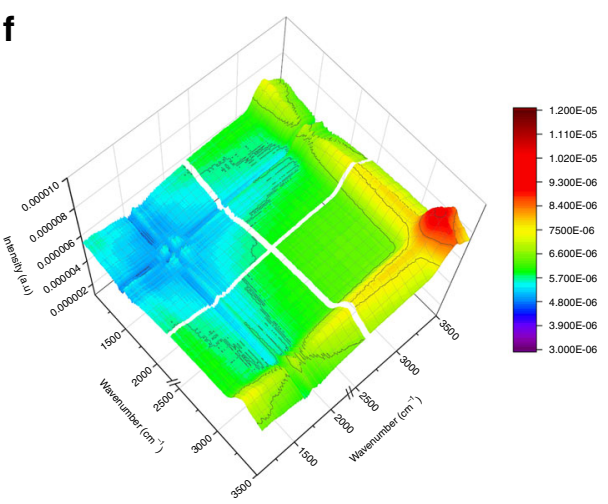

h

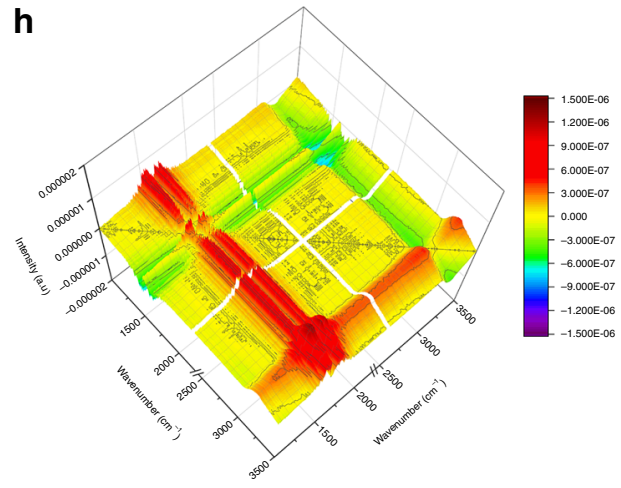

Fig. 6 Electrochemical in situ Fourier transform-infrared (FTIR) spectroscopy of anode-associated a control membrane (R-M: membrane without potential applied) and $\mathbf{b}$ electromembrane (R-0.3: membrane with $-0.30-\mathrm{V}$ potential applied) between 1300 and $1900 \mathrm{~cm}^{-1}$, as well as c control membrane (R-M) and $\mathbf{d}$ electromembrane (R-0.3) between 3100 and $3450 \mathrm{~cm}^{-1}$ with varying potentials from -0.8 to $0.2 \mathrm{~V}$. Synchronous $2 \mathrm{D}$ correlation maps generated from FTIR analysis of anode-associated $\mathbf{e}$ control membranes and $\mathbf{f}$ electromembrane. Asynchronous 2D correlation maps generated of anode-associated $\mathbf{g}$ control membranes (R-M) and $\mathbf{h}$ electromembrane (R-0.3). (Source data are provided as a Source Data file.) 
of the bands around 1550 (stretching vibration of $\mathrm{C}-\mathrm{N}$ in amide II) and $1650 \mathrm{~cm}^{-1}$ (stretching vibration of the $\mathrm{C}=\mathrm{O}$ group in amide I) increased with the potential shifting from -0.8 to $0.2 \mathrm{~V}$, which was a result of the polarization of $\mathrm{C}-\mathrm{N}$ and $\mathrm{C}=\mathrm{O}$ in amide groups, while the decrease in the intensities of the bands around $3300 \mathrm{~cm}^{-1}$ (stretching vibration of the $\mathrm{N}-\mathrm{H}$ group) was a result of the depolarization of $\mathrm{N}-\mathrm{H}^{33,34}$. The electric susceptibility is proportional to the relative dielectric constant that reflects the electron-storage capacity for a dielectric ${ }^{35}$. Therefore, with the increase in potential from -0.8 to $0.2 \mathrm{~V}$, the polarization intensity of amide groups of sludge cake layer of the control membrane increased, implying that the potential increased the electronstorage capacity of the amide groups of sludge cake layer. Comparatively, the intensities of amide groups of the electromembrane showed less changes with the potential, but were still higher than the intensities of the control membrane, which suggested that the amide groups of sludge cake layer of the electromembrane had possessed the residual polarization that was no longer polarized. The remanent polarization of the amide groups in sludge cake layer originated from the anodic potential imposed during the membrane-filter operation, which meant that the sludge cake layer had the higher electron-storage capacity to be involved in the anodic degradation of fouling.

Long-range electron transfer through proteins is a fundamental reaction in energy conversion processes ${ }^{36-38}$, and an applied electric field reportedly provided driving force for electron hopping across proteins with redox cofactors ${ }^{39,40}$, in which the amide groups and the $\mathrm{H}$ bonds can act as relay stations ${ }^{41}$. Therefore, the increased polarization of $\mathrm{C}-\mathrm{N}$ and $\mathrm{C}=\mathrm{O}$ band meant that more electrons of these two bands were in high-energy state likely to participate in the electron transfer in which protein with amide groups might act as a momentous mediator. On the other hand, in the proton-coupled electron transfer of proteins (see Supplementary Fig. 1), some protonated side chains of amino acids such as lysine could release $\mathrm{H}$ radical from the homolysis of $\mathrm{N}-\mathrm{H}$, and then the released $\mathrm{H}$ radical was captured by the nearby $\mathrm{C}=\mathrm{O}$ to form $\cdot \mathrm{C}-\mathrm{O}-\mathrm{H}^{42-44}$. Obviously, the decreased intensity of polarization of the $\mathrm{N}-\mathrm{H}$ group made the homolysis of $\mathrm{N}-\mathrm{H}$ easier due to the distribution of electron cloud and static effect, and the increased intensity of polarization of the $\mathrm{C}=\mathrm{O}$ group also benefited to capture the $\mathrm{H}$ radical released from $\mathrm{N}-\mathrm{H}$ to form the $\mathrm{O}-\mathrm{H}$ bond. Thus, the decreased intensity of the $\mathrm{N}-\mathrm{H}$ bond with the potential indicated an enhanced electron transfer within proteins of the sludge cake layer on the electromembrane. Therefore, with the changed bands above, the residual EPS of the electromembrane possessed a higher electroactivity, including the remnant polarization and the electron transfer capacity, although the majority of EPS has been decomposed. From the analysis of 2DCOS, the synchronous maps (Fig. 6e, f) showed that three predominant autopeaks centered around 1550, 1650, and $3300 \mathrm{~cm}^{-1}$ for the control membrane, and one predominant autopeak centered around $3300 \mathrm{~cm}^{-1}$ for the electro-assisted group, which were consistent with the in situ FTIR spectroscopy. Unobvious peaks presented around 1650 and $1550 \mathrm{~cm}^{-1}$ for the electromembrane indicated that the amide groups were no longer sensitive to the potential change. According to the sequential order rules $^{45}$, the detailed distributions of the bands (see Supplementary Table 2) and their cross-peaks in asynchronous maps (Fig. 6g, h) indicated that the changes in the amide groups were homologous, which further indicated that proteins with the amide groups were the source of these bands. The changes in the amide groups were nonhomologous with the $\mathrm{N}-\mathrm{H}$ group, which indicated that the $\mathrm{N}-\mathrm{H}$ band with the weakened polar intensity was not derived from amide groups, but might be from the side chain of the amide acids to serve as the proton tansfer sites, in agreement with the aforementioned $\mathrm{H}$ radical-coupled electron transfer.
In general, the applied potential not only decomposed the EPS, but also improved the electroactivity of the sludge cake layer. Noteworthily, EPS was a mixture of proteins, polysaccharides, nucleic acids, and other components. Proteins such as pili and cytochromes were reportedly capable of participating in extracellular electron transfer ${ }^{46}$, while some other EPSs such as polysaccharides were rarely reported electroactive. In this study, the enrichment of exoelectrogens with conductive pili, and the improvement of the electron storage and transfer of the proteins could enhance the decomposition of electro-inert EPSs such as polysaccharides on the anode. The alleviation of the fouling further indicated that the redundant EPSs were decomposed in the electromembrane. It also implied that the electro-inert EPSs rather than the modified proteins in the sludge cake layer were the main substrates for anode oxidation. After the operation with anode potential, redundant EPS was decomposed to relieve the membrane fouling, while the electroactive EPS was reserved to maintain an efficient degradation of membrane fouling by anode oxidation. Along with this process, the sludge cake layer transformed to a mesh-like biofilter with efficient anode oxidation capacity (Fig. 7).

Operation with a complicated wastewater. A complicated wastewater composed of protein, macromolecular polysaccharide, humic acid, and so on, was fed to further investigate the feasibility of this method. The overall performances of the three reactors in TMP and COD removal were similar to the above-mentioned results with glucose-based wastewater. Specially, after a sharp increase of TMP in the initial days (Fig. 8a), the TMP of R- 0.3 and R- 0.2 begins to decrease and was finally maintained at low levels (averaging $21.23 \pm 2.41 \mathrm{kPa}$ for R-0.3 and $37.20 \pm 1.58 \mathrm{kPa}$ for R$0.2, n=5)$ during days $38-42$, respectively. For the $\mathrm{R}-\mathrm{M}$, the TMP gradually increased and eventually broke down after day 32 . Differently, the complicated wastewater made the fouling growth more rapid, and it took more days ( 24 days for R- 0.3 and 27 days for R-0.2) for the electroreactors to reach the dynamic equilibriums, the TMP levels of which were also higher than the glucosebased feeding. The effluent TCOD and suspended COD (Fig. 8b, c) of the two electroreactors were lower than those of the control, except in the days that R-M suffered from the high fouling that benefited the interception of particles. The electroreactors still maintained the efficient interception capability to improve the effluent quality even with the alleviation of the membrane fouling. The results indicated that the method by using membrane as the anode was also applicable for the complex wastewater and provided a promising strategy for membrane fouling control. Certainly, the operating parameters need to be optimized for the practical use, which warrants further investigation.

\section{Discussion}

In this study, a strategy was proposed to use CNT membrane as the anode to anti-membrane foulings in the operation of AnMBR. The membrane fouling aggravated in the initial stage in the anode membrane reactors due to the electrostatic adherence. However, along with the operation, the decrease in the TMP across the anode membranes indicated the enhanced anode oxidation of the membrane fouling, while the stable TMP states at low levels actually indicated that the fouling growth and decomposition on the anode membranes achieved the dynamic equilibrium eventually. The sludge cake layer with high electroactivity ensured the efficient anode oxidation of the fouling to decompose the excessive EPS. With the massive decomposition of EPS, the sludge cake layer on the anode membrane became thin and promoted the water flux to lower the TMP. The enrichment of exoelectrogens and the induced electroactivity changes of the EPS in the sludge cake layer were essential for the efficient anode oxidation with the 


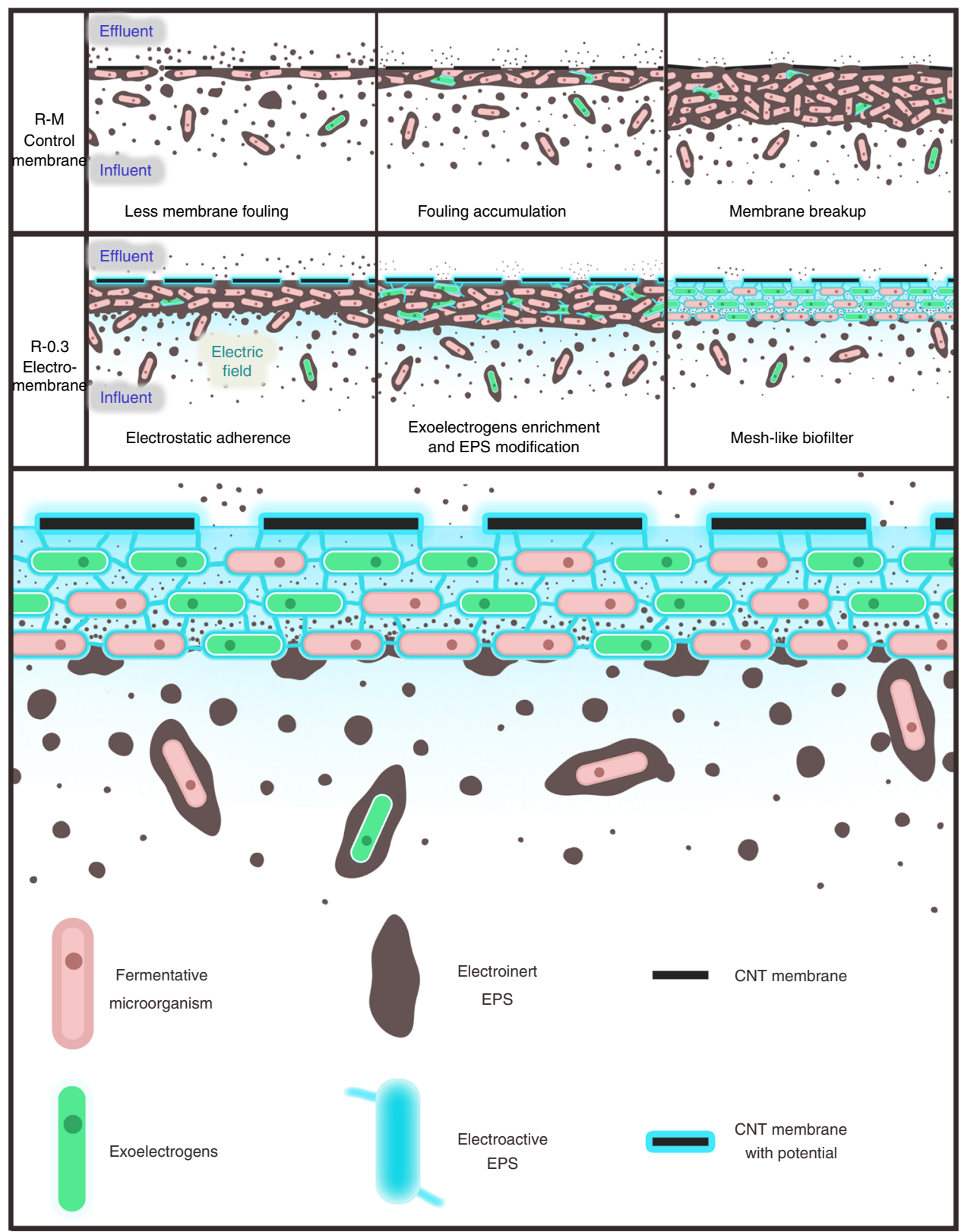

Fig. 7 Membrane fouling transition profiles and the mesh-like biofilter transformed from fouling in the anode membrane

reduction of EPS, which transformed fouling to a mesh-like dynamic biofilter to possess an excellent interception performance as well as a high effluent flux (see more details in Supplementary Discussion). This study showed the feasibility of using the anode membrane solving the membrane fouling.

\section{Methods}

AnEMBR setup and operation. Three anaerobic up-flow anaerobic sludge blanket reactors with $1.0 \mathrm{~L}$ working volume $(\Phi 7.0 \times 26 \mathrm{~cm})$ were applied in this study (see Supplementary Fig. 2). Each reactor was equipped with a CNT membrane module $\left(1.02 \times 10^{-3} \mathrm{~m}^{2}\right.$ working area), six graphite rods $(\Phi 1.0 \times 6.0 \mathrm{~cm})$, and a silver chloride electrode as the anode, cathode, and reference electrode, respectively. According to the previous studies ${ }^{47-50}$, two reactors in which the membranes were imposed with -0.3 and $-0.2 \mathrm{~V}$ anode potential were referred to as $\mathrm{R}-0.3$ and $\mathrm{R}-0.2$, respectively. The third reactor was not imposed with any potential to be used as the control (referred to as R-M).

The detailed preparation and characterizations of the membrane in terms of pore size distribution and morphology are shown in Supplementary Methods, Supplementary Fig. 3, and Supplementary Fig. 4.

All the reactors were run in parallel over the entire operation (38 days) with a HRT of $16 \mathrm{~h}$ and temperature of $38^{\circ} \mathrm{C}$. The seed sludge inoculated in the reactors was collected from an anaerobic digester at a waste sludge treatment plant of Dalian (China). A synthetic glucose-based sewage (see Supplementary Table 3) was fed to the reactors for discussion of the mechanisms, and a synthetic complex sewage (see Supplementary Tables 4-6) was also tested to further verify the feasibility of the antifouling method.

Operation performance. COD of the sludge was measured according to Standard Methods for the Examination of Water and Wastewater ${ }^{51,52}$. The current signals were recorded by the electrochemical station (CHI660D, Shanghai Chenhua Ltd., China) that also imposed the anode potential on the membranes. The voltages between the anode and cathode electrode were recorded by a digital gathering module (ZEAL, China). The trans-membrane pressure (TMP) was detected by a paperless recorder (Asmik, China) per second to represent the membrane fouling condition.

Optical detection. Confocal laser-scanning microscopy (CLSM) (Fluoview FV1000, Olympus, Germany) was employed to visualize the distribution of nucleic acids, proteins, and polysaccharides on the sludge cake layers, and the procedures in detail are shown in Supplementary Methods (Sludge Cake Layer Staining). After freeze-drying for $72 \mathrm{~h}$ at $-50^{\circ} \mathrm{C}$, the thickness of the membranes with sludge cake layer was observed with an optical microscope (Olympus IX83), and the 
R-M: Membrane without potential applied

R-0.3: Membrane with $-0.30 \mathrm{~V}$ potential applied

R-0.2: Membrane with $-0.20 \mathrm{~V}$ potential applied

a

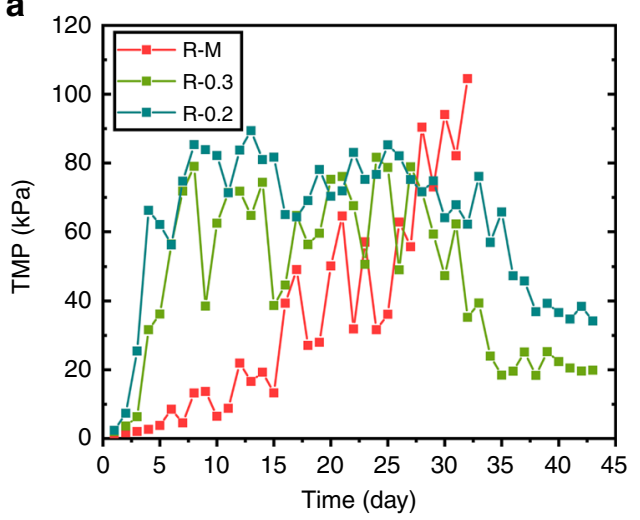

b

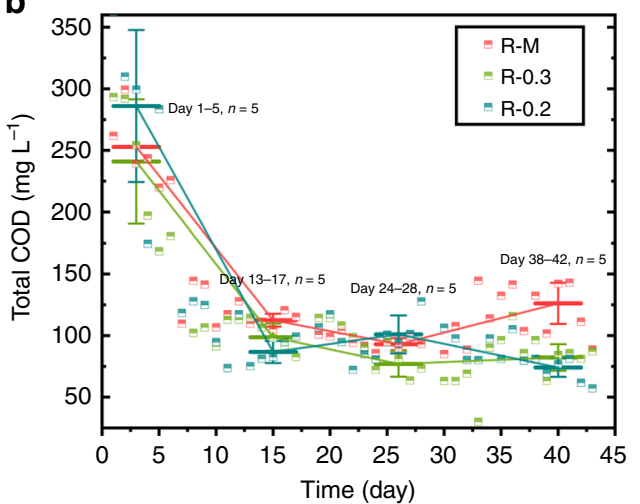

C

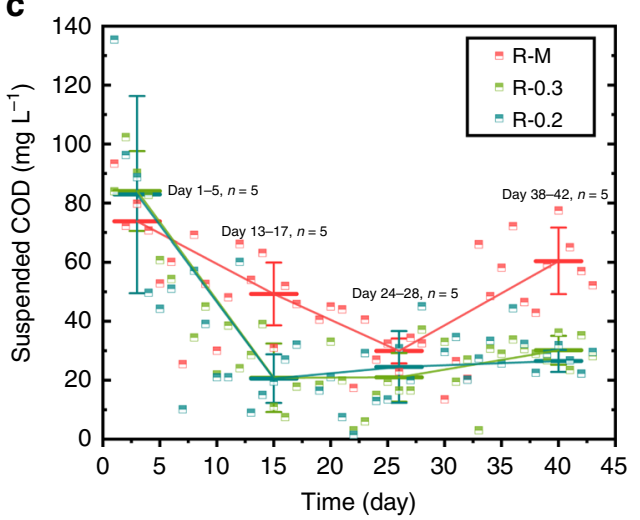

Fig. 8 Reactor performances along operation. a TMP, b total COD, and c suspended COD profiles of the control reactor (R-M: membrane without potential applied) and the electromembrane reactors R-0.3 (membrane with $-0.30-\mathrm{V}$ potential applied) and R-0.2 (membrane with $-0.20-\mathrm{V}$ potential applied). (Numbers that follow the \pm signs are standard deviation (SD) in this study. Error bars in (b) and (c) are from Day 1 to $5(n=5)$, from Day 13 to $17(n=5)$, from Day 24 to $28(n=5)$, and from Day 38 to 42 $(n=5)$. Source data are provided as a Source Data file.)

morphologies and structures of the sludge cake layer were also observed by fieldemission SEM (FE-SEM, HitachiS-4800).

Electrochemical measurements. $\mathrm{CV}$ was performed with the workstation $(\mathrm{CHI}$ 660 , Chenhua Instrument, China) in the range of 0.2 to $-0.8 \mathrm{~V}$ at scan rates of $5 \mathrm{mV} / \mathrm{s}$ in PBS solution, respectively. Electrochemical impedance spectroscopy (EIS) was conducted over a frequency range of $1000 \mathrm{kHz}$ to $0.01 \mathrm{~Hz}$, with a sinusoidal perturbation of $10-\mathrm{mV}$ amplitude, to analyze the internal impedances of the membranes.
Microbial community. The procedures and conditions of the microbial community are detailed in Supplementary Methods.

Outermost membrane surfaces. The vibrational transition behaviors of the outermost surface of the membrane during electrochemical reactions were characterized by electrochemical in situ FTIR spectroscopy with a FTIR spectrometer (Bruker VERTEX 70). With potentials shifting from -0.8 to $0.2 \mathrm{~V}$ as the external perturbation, two-dimensional correlation spectroscopy (2DCOS) was conducted and analyzed. The set and methods in detail are shown in Supplementary Methods (In situ Fourier Transform Infrared Spectroscopy Spectra). The detailed procedures and conditions of in situ FTIR measurement are shown in Supplementary Methods.

Characterization of chemical and biomolecular materials. The chemical reagents used in this study were in high purity to ensure the reliability of the results.

Reporting summary. Further information on research design is available in the Nature Research Reporting Summary linked to this article.

\section{Data availability}

All data generated or analyzed during this study are included in this published article and its supplementary information files. The source data underlying Figs. 1a-e, 4a, b, 5, 6a, b, $8 \mathrm{a}-\mathrm{c}$, Table 1, Table 2, and Supplementary Fig. 3 are provided as a Source Data file. The datasets generated during and/or analyzed during this study are available in the Open Science Framework repository [https://osf.io/u4pwr/].

Received: 8 April 2019; Accepted: 3 October 2019; Published online: 24 October 2019

\section{References}

1. Lin, H. et al. A review on anaerobic membrane bioreactors: applications, membrane fouling and future perspectives. Desalination 314, 169 (2013).

2. Lin, H., Chen, J., Wang, F., Ding, L. \& Hong, H. Feasibility evaluation of submerged anaerobic membrane bioreactor for municipal secondary wastewater treatment. Desalination 280, 120 (2011).

3. Jeison, D. \& van Lier, J. B. Cake formation and consolidation: main factors governing the applicable flux in anaerobic submerged membrane bioreactors (AnSMBR) treating acidified wastewaters. Sep. Purif. Technol. 56, 71 (2007).

4. Gao, W. J., Lin, H. J., Leung, K. T., Schraft, H. \& Liao, B. Q. Structure of cake layer in a submerged anaerobic membrane bioreactor. J. Membrane Sci. 374, 110 (2011).

5. Yu, H. et al. Surface modification of polypropylene microporous membrane to improve its antifouling characteristics in an SMBR: air plasma treatment. J. Membrane Sci. 311, 216 (2008).

6. Sainbayar, A., Kim, J. S., Jung, W. J., Lee, Y. S. \& Lee, C. H. Application of surface modified polypropylene membranes to an anaerobic membrane bioreactor. Environ. Technol. 22, 1035 (2001)

7. Sui, P., Wen, X. \& Huang, X. Membrane fouling control by ultrasound in an anaerobic membrane bioreactor. Front. Environ. Sci. Eng. China 1, 362 (2007)

8. Katuri, K. P. et al. A novel anaerobic electrochemical membrane bioreactor (AnEMBR) with conductive hollow-fiber membrane for treatment of loworganic strength solutions. Environ. Sci. Technol. 48, 12833 (2014).

9. Werner, C. M. et al. Graphene-coated hollow fiber membrane as the cathode in anaerobic electrochemical membrane bioreactors-effect of configuration and applied voltage on performance and membrane fouling. Environ. Sci. Technol. 50, 4439 (2016).

10. Yang, Y., Qiao, S., Jin, R., Zhou, J. \& Quan, X. Novel anaerobic electrochemical membrane bioreactor with a CNTs hollow fiber membrane cathode to mitigate membrane fouling and enhance energy recovery. Environ. Sci. Technol. 53, 1014 (2019).

11. Metzger, U., Le-Clech, P., Stuetz, R. M., Frimmel, F. H. \& Chen, V. Characterisation of polymeric fouling in membrane bioreactors and the effect of different filtration modes. J. Membrane Sci. 301, 180 (2007).

12. Ki, D., Popat, S. C., Rittmann, B. E. \& Torres, C. I. H2O2 production in microbial electrochemical cells fed with primary sludge. Environ. Sci. Technol. 51, 6139 (2017).

13. Yu, Q., Jin, X. \& Zhang, Y. Sequential pretreatment for cell disintegration of municipal sludge in a neutral Bioelectro-Fenton system. Water Res. 135, 44 (2018).

14. Zhao, Z. et al. Enhanced decomposition of waste activated sludge via anodic oxidation for methane production and bioenergy recovery. Int. Biodeterior. Biodegrad. 106, 161 (2016).

15. Prindle, A. et al. Ion channels enable electrical communication in bacteria communities. Nature 527, 59 (2015). 
16. Lovley, D. R. Powering microbes with electricity: direct electron transfer from electrodes to microbes. Env. Microbiol. Rep. 3, 27 (2011).

17. Lin, H. J. et al. Sludge properties and their effects on membrane fouling in submerged anaerobic membrane bioreactors (SAnMBRs). Water Res. 43, 3827 (2009).

18. Mahendran, B., Liss, S. N., Liao, B. \& Lin, H. Surface properties of biofouled membranes from a submerged anaerobic membrane bioreactor after cleaning. J. Environ. Eng. 137, 504 (2011).

19. Ding, A., Yang, Y., Sun, G. \& Wu, D. Impact of applied voltage on methane generation and microbial activities in an anaerobic microbial electrolysis cell (MEC). Chem. Eng. J. 283, 260 (2016).

20. Xiao, Y. et al. Extracellular polymeric substances are transient media for microbial extracellular electron transfer. Sci. Adv. 3, el700623 (2017).

21. Xiao, Y. \& Zhao, F. Electrochemical roles of extracellular polymeric substances in biofilms. Current Opinion in. Curr. Opin. Electrochem. 4, 206 (2017).

22. CHEN, J., YAN, F., DAI, Z. \& JU, H. Reagentless amperometric immunosensor for human chorionic gonadotrophin based on direct electrochemistry of horseradish peroxidase. Biosens. Bioelectron. 21, 330 (2005).

23. Karthikeyan, R. et al. Interfacial electron transfer and bioelectrocatalysis of carbonized plant material as effective anode of microbial fuel cell. Electrochim. Acta 157, 314 (2015).

24. Babauta, J. T. \& Beyenal, H. Use of a small overpotential approximation to analyze Geobacter sulfurreducens biofilm impedance. J. Power Sources 356, 549 (2017).

25. Lovley, D. R. et al. In (ed. Robert K. Poole) Advances in Microbial Physiology (Academic Press, 2011), pp. 1.

26. Malvankar, N. S. et al. Tunable metallic-like conductivity in microbial nanowire networks. Nat. Nanotechnol. 6, 573 (2011).

27. Summers, Z. M. et al. Direct exchange of electrons within aggregates of an evolved syntrophic coculture of anaerobic bacteria. Science 330, 1413 (2010).

28. Rotaru, A. et al. A new model for electron flow during anaerobic digestion: direct interspecies electron transfer to Methanosaeta for the reduction of carbon dioxide to methane. Energy Environ. Sci. 7, 408 (2014).

29. Morita, M. et al. Potential for direct interspecies electron transfer in methanogenic wastewater digester aggregates. MBIO 2, el11 (2011).

30. Maspolim, Y., Zhou, Y., Guo, C., Xiao, K. \& Ng, W. J. The effect of pH on solubilization of organic matter and microbial community structures in sludge fermentation. Bioresource Technol. 190, 289 (2015).

31. Yamada, T. Anaerolinea thermolimosa sp. nov., Levilinea saccharolytica gen. nov., sp. nov. and Leptolinea tardivitalis gen. nov., sp. nov., novel filamentous anaerobes, and description of the new classes Anaerolineae classis nov. and Caldilineae classis nov. in the bacterial phylum Chloroflexi. Int. J. Syst. Evol. Microbiol. 56, 1331 (2006).

32. Drancourt, M., Bollet, C., Carta, A. \& Rousselier, P. Phylogenetic analyses of Klebsiella species delineate Klebsiella and Raoultella gen. nov., with description of Raoultella ornithinolytica comb. nov., Raoultella terrigena comb. nov. and Raoultella planticola comb. nov. Int J. Syst. Evol. Microbiol. 51, 925 (2001).

33. Yu, L., Yuan, Y., Chen, S., Zhuang, L. \& Zhou, S. Direct uptake of electrode electrons for autotrophic denitrification by Thiobacillus denitrificans. Electrochem. Commun. 60, 126 (2015).

34. Evora, M. C. et al. Comparação de técnicas FTIR de transmissão, reflexão e fotoacústica na análise de poliamida-6, reciclada e irradiada. Polímeros 12, 60 (2002).

35. Dubois, V., Umari, P. \& Pasquarello, A. Dielectric susceptibility of dipolar molecular liquids by ab initio molecular dynamics: application to liquid $\mathrm{HCl}$. Chem. Phys. Lett. 390, 193 (2004).

36. Lin, J., Balabin, I. A. \& Beratan, D. N. The nature of aqueous tunneling pathways between electron-transfer proteins. Science 310, 1311 (2005).

37. Chen, X. et al. Water promoting electron hole transport between tyrosine and cysteine in proteins via a special mechanism: double proton coupled electron transfer. J. Am. Chem. Soc. 136, 4515 (2014).

38. Ing, N. L., El-Naggar, M. Y. \& Hochbaum, A. I. Going the distance: long-range conductivity in protein and peptide bioelectronic materials. J. Phys. Chem. B 122, 10403 (2018).

39. Forster, R. J., Walsh, D. A., Mano, N., Mao, F. \& Heller, A. Modulating the redox properties of an osmium-containing metallopolymer through the supporting electrolyte and cross-linking. Langmuir 20, 862 (2004).

40. Akhoury, A., Bromberg, L. \& Hatton, T. A. Interplay of electron hopping and bounded diffusion during charge transport in redox polymer electrodes. J. Phys. Chem. B 117, 333 (2013).

41. Lauz, M., Eckhardt, S., Fromm, K. M. \& Giese, B. The influence of dipole moments on the mechanism of electron transfer through helical peptides. Phys. Chem. Chem. Phys. 14, 13785 (2012).

42. Perkins, C. W. et al. An electrically neutral.sigma.-sulfuranyl radical from the homolysis of a perester with neighboring sulfenyl sulfur: 9-S-3 species. J. Am. Chem. Soc. 102, 7753 (1980).
43. Chen, X. \& Bu, Y. Single- versus multi-proton-coupled Rydberg-state electron transfer in amine clusters. J. Phys Chem C 118, 18861 (2014).

44. Savee, J. D., Mann, J. E. \& Continetti, R. E. Stability of the ground and lowlying vibrational states of the ammonium radical. J. Phys. Chem. Lett. 4, 3683 (2013).

45. Chen, W., Habibul, N., Liu, X., Sheng, G. \& Yu, H. FTIR and synchronous fluorescence heterospectral two-dimensional correlation analyses on the binding characteristics of copper onto dissolved organic matter. Environ. Sci. Technol. 49, 2052 (2015).

46. Lee, D. D., Prindle, A., Liu, J. \& Süel, G. M. SnapShot: electrochemical communication in biofilms. Cell 170, 214 (2017).

47. Yang, G. et al. Anode potentials regulate Geobacter biofilms: new insights from the composition and spatial structure of extracellular polymeric substances. Water Res. 159, 294 (2019).

48. Torres, C. I. et al. Selecting anode-respiring bacteria based on anode potential: phylogenetic, electrochemical, and microscopic characterization. Environ. Sci. Technol. 43, 9519 (2009).

49. O'Brien, J. P. \& Malvankar, N. S. A Simple and Low-cost Procedure for Growing Geobacter sulfurreducens Cell Cultures and Biofilms in Bioelectrochemical Systems: Geobacter sulfurreducens: Anaerobic Cell Cultures and Biofilms in Bioelectrochemical Systems Curr Protoc Microbiol. 43, A.4K.1 (2016). https://doi.org/10.1002/cpmc.20.

50. Bond, D. R. \& Lovley, D. R. Electricity production by Geobacter sulfurreducens attached to electrodes. Appl. Environ. Microbiol. 69, 1548 (2003).

51. Walter, W. G., Standard methods for the examinatioln of water and wastewater (11th ed). Am. J. Public Health Nations Health 51940 (1961).

52. Zhao, Z., Zhang, Y., Li, Y., Zhao, H. \& Quan, X. Electrochemical reduction of carbon dioxide to formate with $\mathrm{Fe}-\mathrm{C}$ electrodes in anaerobic sludge digestion process. Water Res. 106, 339 (2016).

\section{Acknowledgements}

The authors acknowledge the financial support from the National Natural Scientific Foundation of China (21777016 and 51578105) and State Key Research \& Development Plan (2018YFC1900901)

\section{Author contributions}

In this study, Yaobin Zhang contributed to the conception and design of the work; Qilin Yu contributed to the acquisition and analysis of data. Yaobin Zhang and Qilin Yu drafted and revised this work together.

\section{Competing interests}

The authors declare no competing interests.

\section{Additional information}

Supplementary information is available for this paper at https://doi.org/10.1038/s41467019-12838-7.

Correspondence and requests for materials should be addressed to Y.Z.

Peer review information Nature Communications thanks anonymous reviewers for their contributions to the peer review of this work. Peer review reports are available.

Reprints and permission information is available at http://www.nature.com/reprints

Publisher's note Springer Nature remains neutral with regard to jurisdictional claims in published maps and institutional affiliations.

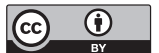

Open Access This article is licensed under a Creative Commons Attribution 4.0 International License, which permits use, sharing adaptation, distribution and reproduction in any medium or format, as long as you give appropriate credit to the original author(s) and the source, provide a link to the Creative Commons license, and indicate if changes were made. The images or other third party material in this article are included in the article's Creative Commons license, unless indicated otherwise in a credit line to the material. If material is not included in the article's Creative Commons license and your intended use is not permitted by statutory regulation or exceeds the permitted use, you will need to obtain permission directly from the copyright holder. To view a copy of this license, visit http://creativecommons.org/ licenses/by/4.0/.

(C) The Author(s) 2019 